\title{
Nacre-inspired Hard and Tough Materials
}

\author{
Huachuan Dua, Ullrich Steiner ${ }^{b}$, and Esther Amstad ${ }^{* a}$
}

\begin{abstract}
Nature fabricates materials with properties that are difficult to reproduce with manmade counterparts. For example, nacre, composed of layers of $\mathrm{CaCO}_{3}$ crystals that are interspaced with small quantities of organic components, is one of the toughest known biomaterials. To produce materials with such fascinating properties, nature has established processes that offer an excellent control over their structure and local composition. Inspired by nacre, a lot of work has been devoted to the fabrication and characterization of composites with similar structures that nevertheless display distinctly different mechanical properties. The first part of this review summarizes methods used to produce nacre-inspired layered composites, their influence on the composition, structure, and mechanical properties. A key difference between the formation of nacre and that of nacre-inspired materials is the mechanism and kinetics of the formation of the inorganic components. In an endeavor to gain a better control over the mechanical properties of the inorganic platelets contained in nacre-inspired composites, the second part of this review describes methods to control the shape, structure, and orientation of $\mathrm{CaCO}_{3}$ formed in organic scaffolds.
\end{abstract}

Keywords: $\mathrm{CaCO}_{3} \cdot$ Composites $\cdot$ Layered composites $\cdot$ Nacre $\cdot$ Nacre-inspired materials

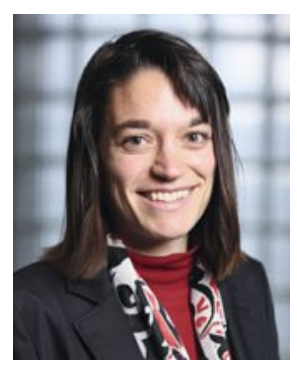

Esther Amstad studied material science at ETH Zurich where she also carried out her $\mathrm{PhD}$ thesis under the supervision of Prof. Marcus Textor; her PhD thesis was devoted to the steric stabilization of iron oxide nanoparticles. As a postdoctoral fellow, she joined the experimental soft condensed matter group of Prof. David A. Weitz at Harvard University where she developed new microfluidic devices to produce different types of emulsion and airborne drops. Since June 2014, she is Tenure Track Assistant Professor at the Institute of Materials at Ecole Polytechnique Fédérale de Lausanne (EPFL), Switzerland, where she heads the Soft Materials Laboratory (SMAL). Inspired by nature, her research team develops drop-based processing routes to produce composites with well-defined structures and locally varying compositions whose mechanical properties closely resemble those of natural materials.

\section{Nacre: A Strong and Tough Natural Material}

Many natural materials display a combination of mechanical properties that are difficult to reproduce with synthetic counterparts. For example, mollusks protect their soft body against predators and foreign bodies with a hard shell whose inner layer is composed of nacre. Nacre displays an exceptional combination of strength and toughness that renders it highly damage resistant. ${ }^{[1]}$ The vast majority of nacre, $95 \mathrm{vol} \%$, is composed of platelets made of aragonite, one of the crystalline $\mathrm{CaCO}_{3}$ polymorphs. These aragonite platelets are arranged into a layered structure, as shown in the scanning electron microscopy (SEM) image in Fig. 1a. To increase the toughness, adjacent aragonite layers are interspaced with thin layers of an organic matrix made of hydrophobic $\beta$-chitin that is coated with hydrophilic silk fibroins and small amounts of acidic peptides, as shown in Fig. 1b. ${ }^{[2]}$ These organic additives increase the toughness of nacre up to 40-fold compared to additive-free aragonite platelets, making it one of the toughest biomaterials. ${ }^{[3]}$ To increase the strength, adjacent aragonite layers are connected by thin $\mathrm{CaCO}_{3}$ bridges. These mineral bridges hamper the lateral displacement of adjacent platelets ${ }^{[4-7]}$ and are most likely a contributing reason for the continuous crystal structure of aragonite platelets across different layers, as schematically illustrated in Fig. 1c. These findings suggest that the fascinating mechanical properties of nacre are a result of an intricate interplay between its hierarchical structure and the composition that repetitively changes on the $\mathrm{nm}$ up to the mm length scale. ${ }^{[8,9]}$ We are far from building materials with similar structures and compositions that controllably change within this length scale range and hence, we cannot tune the mechanical properties of synthetic composites to the same degree. ${ }^{[10]}$ In the following, we summarize some of the more recent developments in the fabrication of nacre-inspired composites and point out their abilities and limitations to control the structure and local composition of these materials. We pay particular attention to their influence on the mechanical properties of the composites.

\section{Nacre-inspired Ceramic Composites}

Fascinated by the mechanical properties of nacre, a lot of efforts have been devoted towards the production of bio-inspired layered 1D, 2D, and 3D composites. ${ }^{[10-13]}$ Most frequently, these materials are composed of an organic matrix that encompasses anisotropic inorganic particles made of $\mathrm{Al}_{2} \mathrm{O}_{3}$ or clay. Due to their anisotropy, platelets can be aligned using isostatic pressures. This is demonstrated, for example, with $\mathrm{Al}_{2} \mathrm{O}_{3}$ platelets that are embedded in an epoxy matrix: If the composite is subjected to an isostatic pressure of $150 \mathrm{MPa}$ during the solidification of epoxy, platelets preferentially align perpendicularly to the applied pressures and thereby can be up-concentrated from $20 \mathrm{vol} \%$ up to $60 \mathrm{vol} \%$. ${ }^{[14]}$ The control over the orientation of platelets is even higher if they are surface modified with superparamagnetic nanoparticles such that they can be oriented using magnetic fields, as shown in Fig. 2a. ${ }^{[15,16]}$ This enhanced control over the platelet orientation results in Young's moduli that are almost twice as high as those of com-

\footnotetext{
${ }^{\star}$ Correspondence: Prof. Dr. E. Amstad 

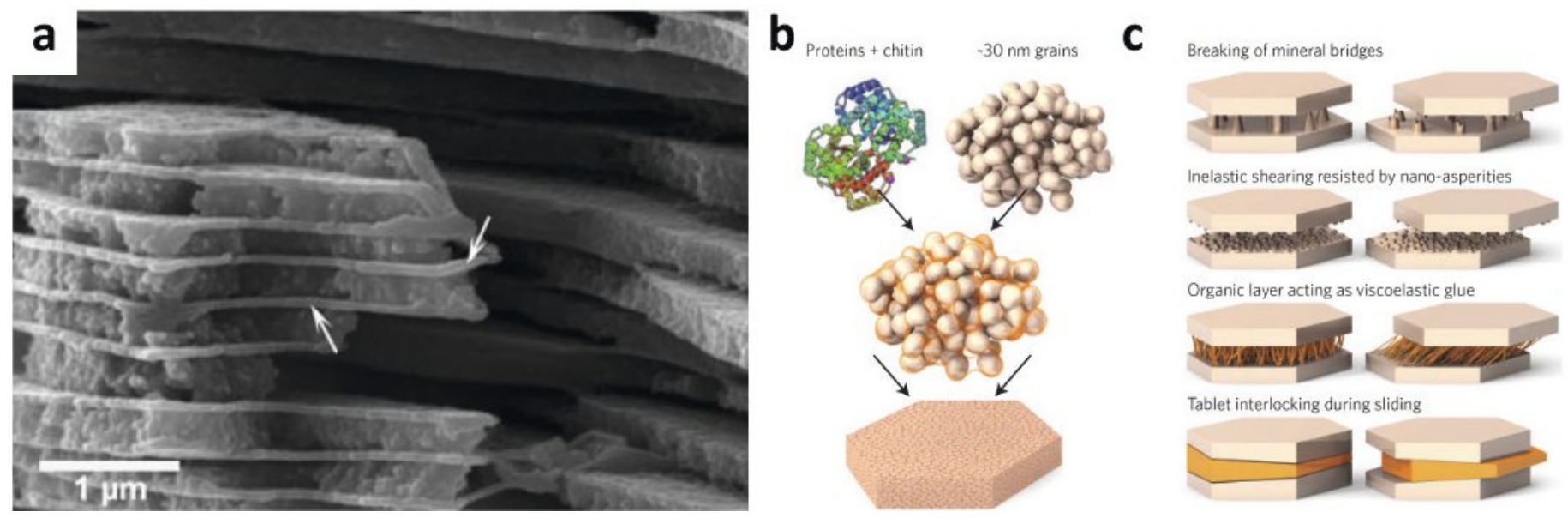

Fig. 1. (a) Scanning electron micrograph of nacre contained in Cephalopod N. pompilius with arrows pointing to the organic interlayers. ${ }^{[2]}$ Schematic illustrations of (b) an aragonite platelet and (c) the connections between them. ${ }^{[8]}$ Figures reproduced with permission of John Wiley and Sons ${ }^{[2]}$ and Springer Nature. ${ }^{[8]}$

posites that have been isostatically pressed, even though the volume fractions of inorganic particles are very similar: Composites encompassing magnetically aligned platelets have Young's moduli that reach up to $50 \mathrm{GPa} .^{[15]}$ This comparison hints to the importance of the orientation of platelets for the mechanical properties of these nacre-inspired composites.

Layered composites can also be formed in the absence of external forces if organic scaffolds are composed of self-assembling polymers. This has been demonstrated, for example, using ethylene glycol 2-ureido-4-pyrimidinone (EG-UPy) as an organic template that was processed in the presence of clay-based platelets. [17] The resulting multi-layered composites, that contain up to $50 \mathrm{wt} \%$ or approximately $30 \mathrm{vol} \%$ clay platelets, are significantly stiffer and stronger than those produced with randomly arranged platelets. Indeed, the Young's modulus of these self-assembled composites is very similar to that reported for composites containing magnetically aligned platelets even though the platelet volume content of the self-assembled composites is about two times lower. A key difference between these composites is the platelet distribution: The position of platelets contained in self-assembled supramolecular polymers is well defined in z-direction whereas that of magnetically aligned platelets is ill-defined in all three directions, as exemplified in Fig. 2b. These results indicate that also the positioning of platelets within composites crucially influences their mechanical properties.

To improve the control over the position of platelets in $z$-direction and to enable the use of a wider range of organic materials as scaffolds, nacre-inspired materials have been fabricated through

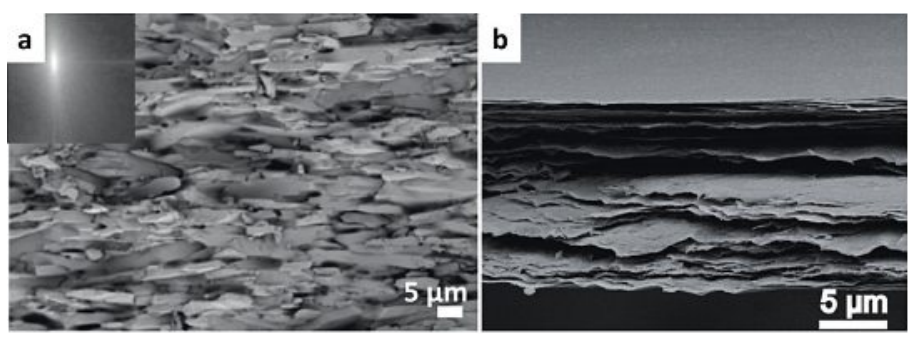

Fig. 2. Nacre-inspired composites containing inorganic platelets. Scanning electron microscopy (SEM) image of a composite containing (a) $\mathrm{Al}_{2} \mathrm{O}_{3}$ platelets surface modified with iron oxide nanoparticles that are embedded in a PMMA matrix. Platelets were oriented using an external magnetic field. ${ }^{[15]}$ (b) SEM image of nanoclay contained in a matrix of the supramolecular poly(oligoethylene glycol methacrylate)-based copolymer that is doped with 2-ureido-4-pyrimidinone (UPy) produced through self-assembly. ${ }^{[17]}$ Figures reproduced with permission of Springer Nature ${ }^{[15]}$ and John Wiley and Sons. ${ }^{[17]}$ layer-by-layer deposition methods, as schematically illustrated in Fig. 3a. ${ }^{[18-21]}$ The resulting composites display a well-defined structure and layer thicknesses that are usually in the $\mu \mathrm{m}$ range albeit layer thicknesses down to a few nanometers have been achieved. ${ }^{[18]}$ However, even if layers are as thick as a few $\mu \mathrm{m}$, the mechanical properties of these composites are rather poor because the organic/inorganic interfaces are typically weak. ${ }^{[18]}$ To increase the mechanical properties of the composites their interfaces have been strengthened for example by modifying the organic scaffold with moieties that have high affinities to the platelets, such as the metal coordinating motive catechol.[20,22] Similarly, the interfacial strength has been increased by modifying the surface of inorganic platelets, for example using chemical groups that form hydrogen ${ }^{[21]}$ or covalent bonds with the organic matrix. ${ }^{[18]}$ This feature was nicely illustrated on clay platelets that have been surface modified with glutaraldehyde to form covalent bonds with the poly(vinyl alcohol) (PVA)-based organic scaffold. The resulting layered composites that contain $50 \mathrm{vol} \%$ clay platelets display Young's moduli up to $106 \mathrm{GPa}$ and tensile strengths as high as 400 $\mathrm{MPa} ;{ }^{[18]}$ these values are clearly superior to those of nacre, as summarized in Fig. 4. This result demonstrates that also the interfacial strength strongly influences the overall mechanical properties of these composites.

Nacre-inspired layered composites can also be produced in a single fabrication step, for example through additive manufacturing. ${ }^{[12]}$ Yet, the spatial resolution of this technology is not yet sufficiently high to introduce the nanometer-sized asperities onto platelet surfaces; these asperities would be needed to achieve good mechanical properties. ${ }^{[23]}$ This shortcoming can be alleviated if nacre-inspired composites are produced through freeze-casting: Upon freezing of an aqueous solution containing inorganic platelets, ice crystallizes and expels the inorganic particles, thereby forming particle-free ice crystals. These crystals are separated by zones containing high concentrations of particles. ${ }^{[24]}$ The direction of the ice crystal growth can be controlled for example by applying temperature gradients, resulting in layered inorganic scaffolds, as schematically illustrated in Fig. 3b. ${ }^{[1,25]}$ After the ice is sublimed, the scaffolds can be back-filled with organic substances to increase the toughness of the composite.[25] The mechanical properties of the resulting layered composites depend on the shape of the inorganic particles: Composites encompassing anisotropic platelets are significantly stiffer and stronger than those containing isotropic particles. ${ }^{[26]}$ Indeed, the tensile strength of nacre-inspired layered composites increases with increasing aspect ratio of the platelets and so does the failure strength. In contrast, the failure strain decreases with increasing platelet aspect ratio because the volume fraction of polymers contained in 


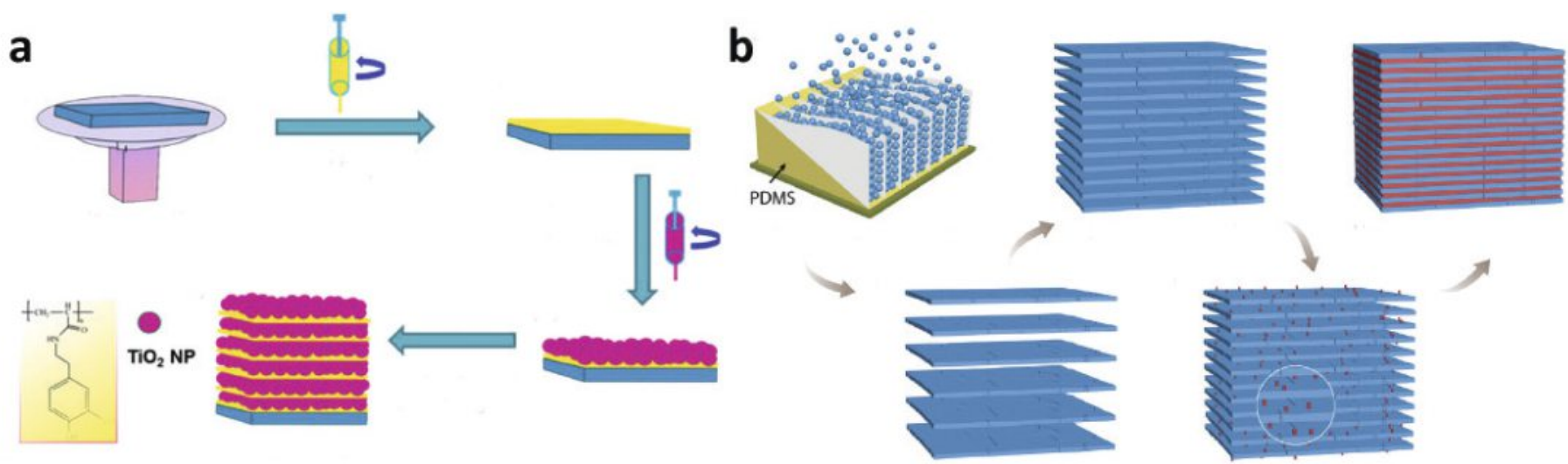

Fig. 3. Fabrication of nacre-inspired materials. (a) Layer-by-layer deposition of DOPA-functionalized polymers and $\mathrm{TiO}_{2}$ nanoparticles. ${ }^{[2]}$ (b) Freeze casting of layered composites results in an inorganic hydroxyapatite scaffold that is back-filled with methacrylate monomers that are subsequently polymerized. ${ }^{[28]}$ Figures reproduced with permission of John Wiley and Sons. ${ }^{[22,28]}$

the composites decreases. ${ }^{[27]}$ Yet, even if the aspect ratio of the platelets is maximized such that the volume content of organics is minimized, these composites are still more flexible than nacre. ${ }^{[27,28]}$ This difference might partially be assigned to the much thicker ceramic and polymeric layers of freeze cast composites compared to those of nacre and the absence of nanoasperities. ${ }^{[25]}$ These results hint at the importance of the layer thickness and surface roughness of the inorganic platelets for the mechanical properties of nacre-inspired materials.

An important reason for the high stiffness measured for nacre are mineral bridges that connect adjacent layers of $\mathrm{CaCO}_{3}$ platelets. ${ }^{[4-7]}$ Inspired by nature, mineral bridges have been formed in nacre-inspired composites to increase their stiffness by sintering the layered inorganic scaffold after the ice has been sublimed.[24,29] If fabricated through this optimized procedure, composites with layer thicknesses of 5-10 $\mu \mathrm{m}$ that contain up to $80 \mathrm{vol} \%$ inorganic platelets display Young's moduli as high as $115 \mathrm{GPa}$ and tensile strengths up to $210 \mathrm{MPa}$. ${ }^{[24,29]}$ These results show feasibility to produce nacre-inspired layered composites with mechanical properties that are superior to those of nacre within one fabrication step, as summarized in Fig. 4.

In summary, the mechanical properties of nacre-inspired materials strongly depend on the dimensions of inorganic particles, their surface roughness, orientation, and positioning within the composites. In addition, the mechanical properties of these composites depend on those of the interfaces between the inorganic particles and the organic scaffold and the connections between inorganic particles. These results demonstrate the importance of the structure of nacre-inspired materials, ranging from the nanometer up to the millimeter length-scale, on their mechanical properties, as schematically illustrated in Figs $1 b$ and 1c. Unfortunately, we are still lacking processes that offer this level of control over the structure of composites over such a wide range of length scales.

\section{3. $\mathrm{CaCO}_{3}$-based Composites}

The degree of control over the structure and local composition is governed by the processing route. Nacre contains organic scaffolds primarily made of hydrophobic $\beta$-chitin and hydrophilic silk fibroin. ${ }^{[30]}$ These scaffolds are infiltrated with amorphous $\mathrm{CaCO}_{3}$ (ACC) particles in the presence of small amounts of soluble organic additives. The densely packed ACC particles subsequently transform into aragonite platelets, as schematically illustrated in Fig. 5a. The resulting micro-sized aragonite platelets are composed of nano-sized crystalline $\mathrm{CaCO}_{3}$ grains that all have the same orientation. The crystalline $\mathrm{CaCO}_{3}$ grains are separated by amorphous grain boundaries containing high concentrations of organic additives, as schematically illustrated in Fig. 1b. ${ }^{[4,31]}$ This nanometer-sized structure and locally varying composition of the aragonite platelets contributes to the high toughness of nacre. ${ }^{[8]}$

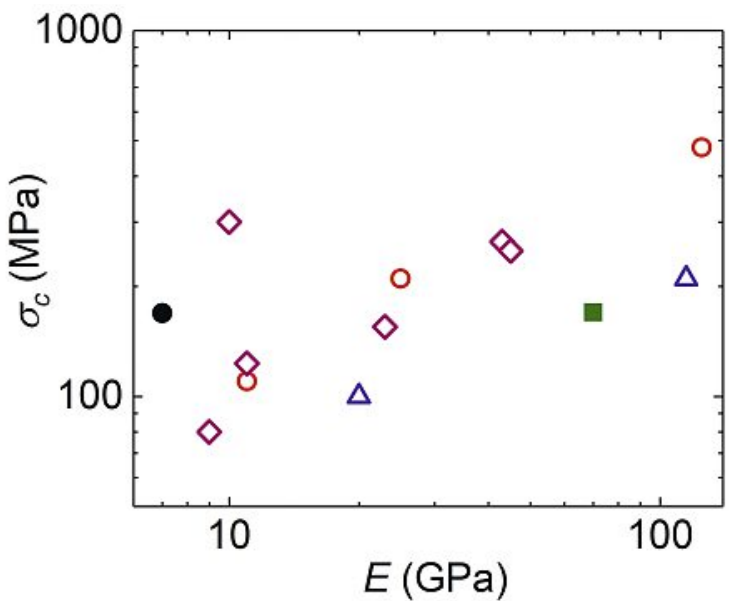

Fig. 4. Overview over the tensile strength $\left(\sigma_{c}\right)$ and Young's modulus $(E)$ of composites containing $\mathrm{Al}_{2} \mathrm{O}_{3}$ or clay particles fabricated through spin coating $(\diamond)$, layer-by-layer deposition $(\bigcirc)$, and freeze casting $(\triangle)$. In addition, $\mathrm{CaCO}_{3}$-containing layered composites fabricated through layer-by-layer deposition are shown $(\bullet)$. For comparison, the mechanical properties of nacre are included $(\square)$.

In contrast, most nacre-inspired materials are produced from assynthesized microparticles that lack nanoasperities and are much more difficult to join through mineral bridges than if produced in situ.

To better control the structure of inorganic particles on a nanometer length scale, $\mathrm{CaCO}_{3}$ particles have been synthesized during the fabrication of nacre-inspired composites. This was achieved, for example, by precipitating $\mathrm{Ca}^{2+}$ and $\mathrm{CO}_{3}^{2-}$ ions in the presence of certain polymers and optionally other additives. ${ }^{[32,33]}$ However, this process offers limited control over the dimensions of the resulting particles. As a result, $\mathrm{CaCO}_{3}$-based particles possess much lower aspect ratios than $\mathrm{Al}_{2} \mathrm{O}_{3}$ or clay platelets used to produce nacre-inspired materials such that the $\mathrm{CaCO}_{3}$-based composites are usually softer than composites containing $\mathrm{Al}_{2} \mathrm{O}_{3}$ or clay platelets.

To more closely mimic the natural fabrication process of nacre, $\mathrm{CaCO}_{3}$-based composites have been fabricated in two steps by forming an organic scaffold that is subsequently mineralized. Using this strategy, free-standing two dimensional (2D) sheets have been produced by infiltrating a thin layer of alginate, crosslinked with $\mathrm{Ca}^{2+}$, with a carbonate source such as $\mathrm{Na}_{2} \mathrm{CO}_{3}$ to form $\mathrm{CaCO}_{3}$ particles inside the alginate matrix. ${ }^{[34]}$ Similarly, three dimensional (3D) composites have been produced from carboxyfunctionalized cellulose nanofibrils that are assembled into 3D hydrogels ${ }^{[35]}$ or from poly(2-hydroxyl methacrylate) (PHEMA) hydrogels. ${ }^{[36]}$ These composites are tough: They reach yield stresses of $200 \mathrm{MPa}^{[35]}$ while they can be strained by up to $8 \%$.[34] 

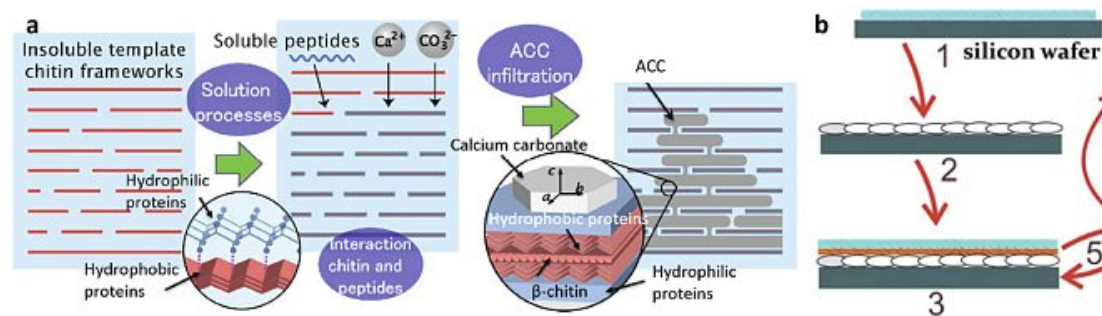

3
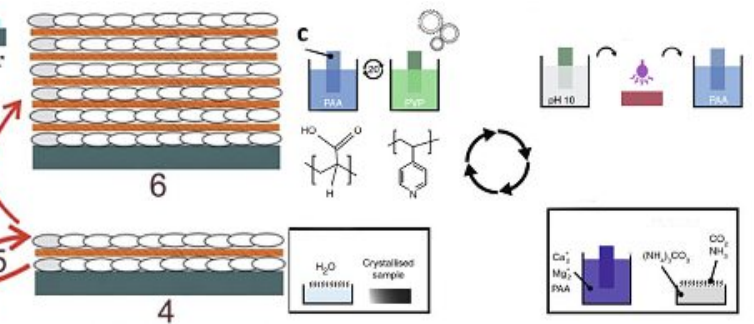

Fig. 5. Formation of $\mathrm{CaCO}_{3}$-based layered materials. (a) Schematic illustration of nacre formation. Chitin-based scaffolds are infiltrated with ACC particles that are subsequently transformed into aragonite platelets. ${ }^{\left[{ }^{[8]}\right.}$ (b) Formation of nanocellulose/ $\mathrm{CaCO}_{3}$ composites through the repetitive de-

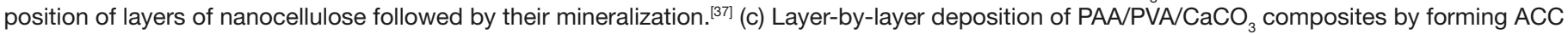
particles inside the matrix and subsequently crystallizing them through exposure of the composites to a humid environment. ${ }^{[39]}$ Figures are reproduced with permission of John Wiley and Sons, ${ }^{[68]}$ the Royal Society of Chemistry, ${ }^{\left[{ }^{[3]}\right]}$ and Springer Nature. ${ }^{[39]}$

However, their Young's moduli are typically at least an order of magnitude lower than that of nacre. Contributing reasons for this difference are the high concentration of organic materials contained in them, that usually exceed $50 \mathrm{wt} \%$, and the limited control over the position of the $\mathrm{CaCO}_{3}$ particles.

To obtain a better control over the position of $\mathrm{CaCO}_{3}$ particles, $\mathrm{CaCO}_{3}$-encompassing composites have been produced through layer-by-layer deposition. To form layers of $\mathrm{CaCO}_{3}$ particles in situ during the sequential deposition of organic layers, standard layer-by-layer deposition protocols must be adjusted. This can be achieved, for example, by depositing a polymeric layer on a substrate, immersing it into a $\mathrm{Ca}^{2+}$-containing solution, and inserting a carbonate source to form an organic/inorganic bilayer. ${ }^{[37]}$ This process can be repeated to generate multilayered composites, as summarized in Fig. 5b. A similar structure can be obtained if the polymer substrate is replaced by amphiphilic carboxy-containing polymers which preferentially adsorb at the surface of a $\mathrm{Ca}^{2+}$ containing liquid that is subsequently supplemented with a carbon source. ${ }^{[38]}$ Optionally, ACC can be transformed into crystals by subjecting the composite to humid environments ${ }^{[39]}$ or elevated temperatures. ${ }^{[40]}$ If the diffusion time of the carbonate source is optimized, the $\mathrm{CaCO}_{3}$ content can be increased up to $93 \mathrm{wt} \%$,[40] such that these composites can display Young's moduli that are relatively high: $14 \mathrm{GPa}$. ${ }^{[37}$ The Young's moduli of $\mathrm{CaCO}_{3}$-based composites can be significantly increased, reaching values up to $43 \mathrm{GPa}$, if the orientation of the $\mathrm{CaCO}_{3}$-based platelets within each layer is controlled for example through freeze-casting.[41] However, these layers are much thicker than the ones contained in nacre and platelets contained in adjacent layers have different orientations, in stark contrast to nacre. These differences likely contribute to the measured differences in mechanical properties.

The concentration of $\mathrm{CaCO}_{3}$ contained in layered composites produced through the diffusion and freeze casting methods can reach values that are similar to those of nacre. Despite of this high $\mathrm{CaCO}_{3}$ concentration, the Young's moduli of these composites are significantly below that of nacre, as summarized in Fig. 4. This difference might in part be attributed to the different structures of synthetic composites and in particular the absence of mineral bridges. To introduce mineral bridges into layered composites, porous organic scaffolds have been developed. These scaffolds have been infiltrated with $\mathrm{Ca}^{2+}$ and $\mathrm{Mg}^{2+}$ ions in the presence of PAA, a carbonate source, and a base to form additive-stabilized ACC particles that have subsequently been crystallized through exposure to a humid environment. This process can be repeated several times to form multilayer structures, as schematically shown in Fig. 5c. ${ }^{[39]}$ Importantly, $\mathrm{CaCO}_{3}$ not only forms between the different layers of the polymer scaffold but also within the pores, resulting in mineral bridges. These mineral bridges offer a better control over the orientation of $\mathrm{CaCO}_{3}$ crystals formed in different layers and minimize their lateral displacement. However, despite of these distinct advantages, the Young's modulus of the resulting composites is $38 \mathrm{GPa}$, a value significantly below that of nacre. A contributing reason for this difference might be the $\mathrm{CaCO}_{3}$ structure: The bio-mimetic composites contained calcite, a polymorph that is softer than aragonite contained in nacre.

To more closely mimic the structure of nacre, natural organic scaffolds have been produced by chemically removing $\mathrm{CaCO}_{3}$ from nacre. The resulting organic scaffolds have been re-mineralized to form composites with structures that closely resemble those of nacre. ${ }^{[42]}$ Interestingly, the re-mineralization is only successful if $\mathrm{CaCO}_{3}$ is formed in the presence of small quantities of soluble organic additives, ${ }^{[43]}$ demonstrating the importance of these additives for the controlled formation of $\mathrm{CaCO}_{3}$ crystals. ${ }^{[7]}$ However, even if organic additives are present, the inorganic platelets that form inside the natural scaffold differ from those of nacre: they are composed of calcite displaying different orientations and not all regions of the scaffold are fully mineralized. As a result of these differences, the mechanical properties of these nacre-mimetic composites are still inferior to those of the natural counterparts. To fabricate materials with mechanical properties that more closely resemble those of nacre, we must obtain a better simultaneous control over the dimensions, structure, and orientation of $\mathrm{CaCO}_{3}$ crystals, their concentration and positioning, the thickness of the different layers, and the connections between different $\mathrm{CaCO}_{3}$-based layers. While significant progress in controlling each of these points individually has been achieved, it is still challenging to control all of them at the same time. To get a step closer to this goal, a better understanding on the influence of additives and organic scaffolds on the formation of $\mathrm{CaCO}_{3}$ is required.

\section{Formation of $\mathrm{CaCO}_{3}$ on Organic Substrates}

The mechanical properties of $\mathrm{CaCO}_{3}$ depend on its structure and the presence of additives. To better understand the influence of the organic scaffold and soluble organic additives on the formation of $\mathrm{CaCO}_{3}$, the mineralization process was studied using twodimensional (2D) substrates. By analogy to the mineralization of $3 \mathrm{D}$ scaffolds, $\mathrm{CaCO}_{3}$-based films only grow on $2 \mathrm{D}$ substrates if appropriate organic additives such as $\mathrm{PAA}^{[44,45]}$ or poly(aspartic acid) ${ }^{[46]}$ are present. ${ }^{[47-49]}$ These soluble organic additives influence the structure and morphology of individual crystalline $\mathrm{CaCO}_{3}$ particles. ${ }^{[50,51]}$ The exact mechanism by which they influence the crystal structure is unclear. For example, it remains to be determined whether some of these additives are incorporated in the $\mathrm{CaCO}_{3}$ particles, and thereby influence their structure. The incorporation of additives into $\mathrm{CaCO}_{3}$-based films could also have important implications for their mechanical properties. For example, the hardness of individual calcite particles significantly increases if small amounts of amino acids are incorporated. [52] By analogy to individual $\mathrm{CaCO}_{3}$ particles, the structure of $\mathrm{CaCO}_{3}$ films depends on the composition of both the insoluble organic substrate and the soluble organic additives. For example, calcite films form on hydroxyl-presenting surfaces like cellulose whereas vaterite films form on amine-presenting surfaces like chitosan, if soluble additives such as PAA are present. ${ }^{[44]}$ Similarly, vater- 
ite films form on styrylpyridinium-modified PVA films if their crosslink density is sufficiently low and calcite films form if the crosslinking density exceeds a threshold value. ${ }^{[53]}$

The composition of the organic scaffold also influences the orientation of the $\mathrm{CaCO}_{3}$ crystals formed on it: A seminal work demonstrated that surfaces presenting certain functionalities, such as carboxyl or hydroxyl groups, favor the transformation of ACC particles into single calcite crystals with well-defined orientations, as shown schematically in Fig. 6a. ${ }^{[54,55]}$ This feature was explored to form crystalline $\mathrm{CaCO}_{3}$ films with orientations that alternatively change over short length scales, ${ }^{[53,56,57]}$ for example, using self-assembled poly[(vinyl alcohol)-co(vinyl acetate)] copolymers, as shown in Fig. $6 b^{[56]}$ or polyrotaxane-modified PVA. ${ }^{[57]}$ The orientation of $\mathrm{CaCO}_{3}$ crystals also depends on the conformation of the polymers and hence on the substrate stiffness: The $c$-axis of vaterite films produced on $\operatorname{poly}(N$-isopropylacrylamide) (PNIPAM) brushes is oriented parallel to the substrate if grown at temperatures above the lower critical solution temperature (LCST), $T>\mathrm{LCST}$, whereas it is oriented perpendicular to the substrate if grown at $T<\mathrm{LCST}$. ${ }^{[58]}$ Hence, the composition of the insoluble organic scaffolds offers a simultaneous control over the structure and orientation of $\mathrm{CaCO}_{3}$ films.

The selective adsorption of $\mathrm{CaCO}_{3}$ on functionalized surfaces results in an additional benefit: It offers control over the shape
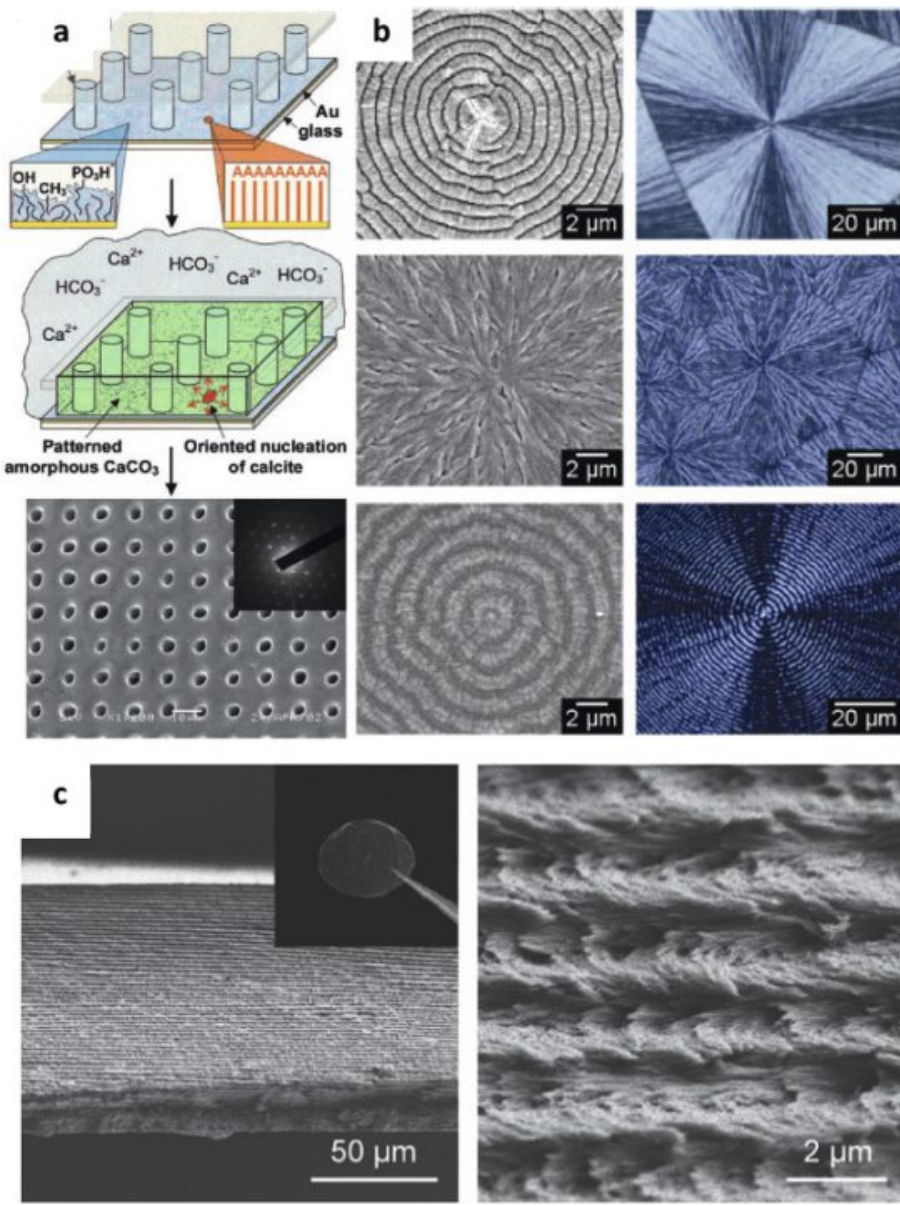

Fig. 6. Formation of $\mathrm{CaCO}_{3}$ crystals with controlled orientations. (a) Schematic illustration of a template used to grow a calcite single crystal that has a well-defined orientation. ${ }^{[54]}$ (b) Left: Scanning electron and right: polarized light microscopy images of calcite grown on a self-assembled poly[(vinyl alcohol)-co(vinyl acetate)] polymer film after annealing at $200^{\circ} \mathrm{C}$ for $10 \mathrm{~min}$ (top), $60 \mathrm{~min}$ (middle) and $120 \mathrm{~min}$ (bottom), ${ }^{[56]}$ (c) SEM images of the cross section of $\mathrm{CaCO}_{3}$ crystals grown on a liquid crystalline chitin/PAA film. ${ }^{[64]}$ Figures reproduced with permission of the American Association for the Advancement of Science, ${ }^{[54]}$ Springer Nature, ${ }^{[56]}$ and John Wiley and Sons. ${ }^{[64]}$ of the $\mathrm{CaCO}_{3}$ films. Taking advantage of this feature, $\mathrm{CaCO}_{3}$ films with well-defined shapes were grown on surfaces patterned with polymer brushes presenting carboxylic acids, ${ }^{[59]}$ urease, ${ }^{[60]}$ or methacrylate-block methylphenylsilane-block-hydroxyethyl methacrylate) (PHEMA-PMPS-PHEMA). ${ }^{[61]}$ The shape of $\mathrm{CaCO}_{3}$-based materials was also controlled in $3 \mathrm{D}$ using polymeric substrates with well-defined structures such as epoxy resins, ${ }^{[62]}$ PHEMA hydrogels, ${ }^{[36]}$ or even self-assembling polymers such as poly(styrene)-b-poly(isoprene) block-copolymers, ${ }^{[63]}$ and liquid crystalline chitin whiskers, as exemplified in Fig. 6c. ${ }^{64]}$ These studies nicely show that the structure, orientation, shape, and position of $\mathrm{CaCO}_{3}$ crystals can be controlled with the chemistry and morphology of the organic scaffold and the presence of soluble organic additives. However, these methods have never been systematically used to form nacre-inspired $\mathrm{CaCO}_{3}$-containing layered composites that have the potential to display improved mechanical properties.

\section{Outlook}

Nature established processes that offer a close control over the structure and local composition of materials, thereby imparting excellent mechanical properties to them. The close control over the structure and local composition of materials achieved by nature allows the fabrication of composites with fascinating mechanical properties by using only a very limited number of elements. We are far from obtaining this level of control in nacre-inspired materials and hence, cannot fully leverage our advantage to build bio-inspired materials from a much wider range of materials yet. A key difference between nacre and nacre-inspired materials is the formation process. Inorganic particles contained in manmade composites are usually fabricated in bulk before they are assembled into composites. By contrast, nature produces aragonite platelets during the formation of nacre by depositing small ACC particles into well-defined organic scaffolds that subsequently transform into aragonite platelets. Thereby, nature obtains an excellent control over the structure, composition, and orientation of the $\mathrm{CaCO}_{3}$-based aragonite crystals at different length scales such that they possess mechanical properties that largely exceed single crystal counterparts. ${ }^{[8,65]}$ To synthetically produce $\mathrm{CaCO}_{3}$-based platelets with similar properties, we must obtain a better control over their structure on the nanometer up to the micrometer length scale, their orientation, and their positioning within the organic scaffold. To achieve this goal, we must gain a better understanding of the influence of soluble additives, the scaffold, and processing conditions on these parameters. Some of these aspects have been studied for individual particles. ${ }^{[66,67]}$ However, very little research has been performed on the influence of these parameters on the structure and composition of ensembles of ACC particles and their transformation into crystalline materials. This information would open up new possibilities to fabricate layered composites whose structure and local composition can be controlled with a much tighter precision. This knowhow would offer a better control over their properties and might enable the fabrication of the next generation of bio-inspired materials whose properties are more similar or even superior to those of natural counterparts.

\section{Acknowledgements}

This work was financially supported by the NCCR Bio-Inspired Materials.

Received: September 21, 2018

[1] I. Corni, T. J. Harvey, J. A. Wharton, K. R. Stokes, F. C. Walsh, R. J. K Wood, Bioinspiration \& Biomimetics 2012, 7, DOI: 10.1088/17483182/7/3/031001.

[2] L. Addadi, D. Joester, F. Nudelman, S. Weiner, Chemistry Eur. J. 2006, 12 981, DOI: $10.1002 /$ chem.200500980. 
[3] U. G. K. Wegst, M. F. Ashby, Philos. Mag. 2004, 84, 2167, DOI: $10.1080 / 14786430410001680935$.

[4] A. G. Checa, J. H. E. Cartwright, M.-G. Willinger, J. Struct. Biol. 2011, 176, 330, DOI: 10.1016/j.jsb.2011.09.011.

[5] F. Song, Y. L. Bai, J. Mater. Res. 2003, 18, 1741, DOI: 10.1557/ JMR.2003.0239.

[6] K. S. Katti, D. R. Katti, S. M. Pradhan, A. Bhosle, J. Mater. Res. 2005, 20 , 1097, DOI: 10.1557/JMR.2005.0171.

[7] Y. Oaki, A. Kotachi, T. Miura, H. Imai, Adv. Funct. Mater. 2006, 16, 1633, DOI: 10.1002/adfm.200600262.

[8] U. G. K. Wegst, H. Bai, E. Saiz, A. P. Tomsia, R. O. Ritchie, Nat. Mater. 2015, 14, 23, DOI: $10.1038 /$ nmat4089.

[9] R. O. Ritchie, Nat. Mater. 2011, 10, 817, DOI: 10.1038/nmat3115.

[10] N. A. Yaraghi, D. Kisailus, Annu. Rev. Phys. Chem. 2018, 69, 23, DOI: 10.1146/annurev-physchem-040215-112621.

[11] H. Zhao, Z. Yang, L. Guo, NPG Asia Mater. 2018, 10, 1, DOI: 10.1038/ s41427-018-0009-6.

[12] R. Yadav, M. Naebe, X. Wang, B. Kandasubramanian, Ind. Eng. Chem. Res. 2017, 56, 10516, DOI: 10.1021/acs.iecr.7b01679.

[13] J. Zhang, W. Feng, H. Zhang, Z. Wang, H. A. Calcaterra, B. Yeom, P. A. Hu, N. A. Kotov, Nat. Commun. 2016, 7, 10701, DOI: 10.1038/ncomms10701.

[14] O. Oner Ekiz, A. F. Dericioglu, H. Kakisawa, Mater. Sci. Eng. C 2009, 29, 2050, DOI: 10.1016/j.msec.2009.04.001.

[15] H. L. Ferrand, F. Bouville, T. P. Niebel, A. R. Studart, Nat. Mater. 2015, 14, 1172, DOI: $10.1038 / \mathrm{nmat} 4419$.

[16] R. M. Erb, R. Libanori, N. Rothfuchs, A. R. Studart, Science 2012, 335, 199, DOI: $10.1126 /$ science. 1210822 .

[17] B. L. Zhu, N. Jasinski, A. Benitez, M. Noack, D. Park, A. S. Goldmann, C. Barner-Kowollik, A. Walther, Angew. Chem. Int. Ed. 2015, 54, 8653, DOI: 10.1002/anie.201502323

[18] P. Podsiadlo, A. K. Kaushik, E. M. Arruda, A. M. Waas, B. S. Shim, J. D. Xu, H. Nandivada, B. G. Pumplin, J. Lahann, A. Ramamoorthy, N. A. Kotov, Science 2007, 318, 80, DOI: 10.1126/science.1143176.

[19] Z. Y. Tang, N. A. Kotov, S. Magonov, B. Ozturk, Nat. Mater. 2003, 2, 413, DOI: $10.1038 /$ nmat906.

[20] P. Podsiadlo, Z. Q. Liu, D. Paterson, P. B. Messersmith, N. A. Kotov, Adv. Mater. 2007, 19, 949, DOI: 10.1002/adma.200602706.

[21] L. J. Bonderer, A. R. Studart, L. J. Gauckler, Science 2008, 319, 1069, DOI: 10.1126/science. 1148726 .

[22] F. Liaqat, M. N. Tahir, E. Schechtel, M. Kappl, G. K. Auernhammer, K. Char, R. Zentel, H.-J. Butt, W. Tremel, Macromol. Rap. Commun. 2015, 36, 1129, DOI: $10.1002 /$ marc.201400706.

[23] G. X. Gu, F. Libonati, S. D. Wettermark, M. J. Buehler, J. Mech. Behav. Biomed. Mater. 2017, 76, 135, DOI: 10.1016/j.jmbbm.2017.05.007.

[24] M. E. Launey, E. Munch, D. H. Alsem, H. B. Barth, E. Saiz, A. P. Tomsia, R. O. Ritchie, Acta Mater. 2009, 57, 2919, DOI: 10.1016/j.actamat.2009.03.003.

[25] S. Deville, E. Saiz, R. K. Nalla, A. P. Tomsia, Science 2006, 311, 515, DOI: 10.1126/science.1120937.

[26] P. M. Hunger, A. E. Donius, U. G. K. Wegst, J. Mech. Behav. Biomed. Mater. 2013, 19, 87, DOI: 10.1016/j.jmbbm.2012.10.013.

[27] P. Das, J. M. Malho, K. Rahimi, F. H. Schacher, B. C. Wang, D. E. Demco, A. Walther, Nat. Comm. 2015, 6, DOI: 10.1038/ncomms6967.

[28] H. Bai, F. Walsh, B. Gludovatz, B. Delattre, C. L. Huang, Y. Chen, A. P. Tomsia, R. O. Ritchie, Adv. Mater. 2016, 28, 50, DOI: 10.1002/adma.201504313.

[29] E. Munch, M. E. Launey, D. H. Alsem, E. Saiz, A. P. Tomsia, R. O. Ritchie, Science 2008, 322, 1516, DOI: 10.1126/science.1164865

[30] Y. Levi-Kalisman, G. Falini, L. Addadi, S. Weiner, J. Struct. Biol. 2001, 135, 8, DOI: $10.1006 /$ jsbi.2001.4372.

[31] X. D. Li, Z. H. Xu, R. Z. Wang, Nano Letters 2006, 6, 2301, DOI: 10.1021/ nl061775u.

[32] D. Gebauer, V. Oliynyk, M. Salajkova, J. Sort, Q. Zhou, L. Bergstrom, G. Salazar-Alvarez, Nanoscale 2011, 3, 3563, DOI: 10.1039/c1nr10681c.

[33] X. Q. Li, H. C. Zeng, Adv. Mater. 2012, 24, 6277, DOI: 10.1002/ adma.201202733.

[34] X. Yuan, W.-C. Nie, C. Xu, X.-H. Wang, Q. Xiao, F. Song, X.-L. Wang, Y.-Z. Wang, Adv. Funct. Mater. 2018, 28, 1704956, DOI: 10.1002/ adfm.201704956.

[35] T. Saito, Y. Oaki, T. Nishimura, A. Isogai, T. Kato, Mater. Horiz. 2014, 1, 321, DOI: $10.1039 / \mathrm{c} 3 \mathrm{mh} 00134 \mathrm{~b}$
[36] X. Cheng, L. B. Gower, Biotechnol. Prog. 2006, 22, 141, DOI: 10.1021/ bp050166+

[37] M. Farhadi-Khouzani, C. Schutz, G. M. Durak, J. Fornell, J. Sort, G. Salazar-Alvarez, L. Bergstrom, D. Gebauer, J. Mater. Chem. A 2017, 5, DOI: $10.1039 / \mathrm{c} 6 \mathrm{ta} 09524 \mathrm{k}$

[38] H. F. Gong, M. Pluntke, O. Marti, P. Walther, L. Gower, H. Colfen, D. Volkmer, Colloids Surf. A Physicochem. Eng. Asp. 2010, 354, 279, DOI: 10.1016/j.colsurfa.2009.08.002.

[39] A. Finnemore, P. Cunha, T. Shean, S. Vignolini, S. Guldin, M. Oyen, U. Steiner, Nat. Comm. 2012, 3, DOI: 10.1038/ncomms1970.

[40] H. Wei, N. Ma, F. Shi, Z. Q. Wang, X. Zhang, Chem. Mater. 2007, 19, 1974, DOI: $10.1021 / \mathrm{cm} 062898 \mathrm{i}$.

[41] L.-B. Mao, H.-L. Gao, H.-B. Yao, L. Liu, H. Cölfen, G. Liu, S.-M. Chen, S.K. Li, Y.-X. Yan, Y.-Y. Liu, S.-H. Yu, Science 2016, 354, 107, DOI: 10.1126/ science.aaf8991.

[42] N. Gehrke, N. Nassif, N. Pinna, M. Antonietti, H. S. Gupta, H. Colfen, Chem. Mater. 2005, 17, 6514, DOI: 10.1021/cm052150k.

[43] K. Gries, F. Heinemann, M. Gummich, A. Ziegler, A. Rosenauer, M. Fritz, Cryst. Growth \& Des. 2011, 11, 729, DOI: 10.1021/cg101240e.

[44] N. Hosoda, T. Kato, Chem. Mater. 2001, 13, 688, DOI: 10.1021/cm000817r

[45] A. Sugawara, T. Ishii, T. Kato, Angew. Chem. Int. Ed. 2003, 42, 5299, DOI: 10.1002/anie.200351541

[46] A. Sugawara, T. Kato, Chem. Commun. 2000, 487, DOI: 10.1039/A909566G.

[47] T. Kato, A. Sugawara, N. Hosoda, Adv. Mater. 2002, 14, 869, DOI: 10.1002/1521-4095(20020618).

[48] T. Kato, Adv. Mater. 2000, 12, 1543, DOI: 10.1002/1521-4095(200010).

[49] T. Kato, T. Suzuki, T. Amamiya, T. Irie, M. Komiyama, H. Yui, Supramol. Sci. 1998, 5, 411, DOI: 10.1016/S0968-5677(98)00041-8.

[50] F. C. Meldrum, S. T. Hyde, J. Cryst. Growth 2001, 231, 544, DOI: 10.1016/ s0022-0248(01)01519-6.

[51] B. Cantaert, Y.-Y. Kim, H. Ludwig, F. Nudelman, N. A. J. M. Sommerdijk, F. C. Meldrum, Adv. Funct. Mater. 2012, 22, 907, DOI: 10.1002/ adfm.201102385.

[52] Y.-Y. Kim, K. Ganesan, P. Yang, A. N. Kulak, S. Borukhin, S. Pechook, L. Ribeiro, R. Kroeger, S. J. Eichhorn, S. P. Armes, B. Pokroy, F. C. Meldrum, Nat. Mater. 2011, 10, 890, DOI: 10.1038/nmat3103.

[53] T. Sakamoto, A. Oichi, Y. Oaki, T. Nishimura, A. Sugawara, T. Kato, Cryst. Growth \& Des. 2009, 9, 622, DOI: 10.1021/cg8009628.

[54] J. Aizenberg, D. A. Muller, J. L. Grazul, D. R. Hamann, Science 2003, 299 , 1205, DOI: $10.1126 /$ science. 1079204.

[55] J. Aizenberg, A. J. Black, G. M. Whitesides, J. Am. Chem. Soc. 1999, 121, 4500, DOI: $10.1021 / \mathrm{ja} 984254 \mathrm{k}$.

[56] T. Sakamoto, A. Oichi, T. Nishimura, A. Sugawara, T. Kato, Polymer J. 2009, 41, 522, DOI: 10.1295/polymj.PJ2009024.

[57] F. Zhu, T. Nishimura, H. Eimura, T. Kato, CrystEngComm 2014, 16, 1496, DOI: 10.1039/C3CE41649F.

[58] Y. Han, T. Nishimura, T. Kato, CrystEngComm 2014, 16, 3540, DOI: 10.1039/C3CE42646G.

[59] S. Tugulu, M. Harms, M. Fricke, D. Volkmer, H. A. Klok, Angew. Chem. Int. Ed. 2006, 45, 7458, DOI: 10.1002/anie. 200602382.

[60] B. Yeom, K. Char, Chem. Mater. 2010, 22, 101, DOI: 10.1021/cm9029566.

[61] D. C. Popescu, E. N. M. van Leeuwen, N. A. A. Rossi, S. J. Holder, J. A. Jansen, N. Sommerdijk, Angew. Chem. Int. Ed. 2006, 45, 1762, DOI: 10.1002/anie. 200502602.

[62] R. J. Park, F. C. Meldrum, Adv. Mater. 2002, 14, 1167, DOI: 10.1002/15214095(20020816)

[63] A. S. Finnemore, M. R. J. Scherer, R. Langford, S. Mahajan, S. Ludwigs, F. C. Meldrum, U. Steiner, Adv. Mater. 2009, 21, 3928, DOI: 10.1002/ adma.200900615.

[64] S. Matsumura, S. Kajiyama, T. Nishimura, T. Kato, Small 2015, 11, 5127, DOI: $10.1002 / \mathrm{smll} .201501083$

[65] H. J. Gao, B. H. Ji, I. L. Jager, E. Arzt, P. Fratzl, PNAS 2003, 100, 5597, DOI: 10.1073/pnas.0631609100.

[66] J. Ihli, P. Bots, A. Kulak, L. G. Benning, F. C. Meldrum, Adv. Funct. Mater 2013, 23, 1965, DOI: 10.1002/adfm.201201742.

[67] Z. Y. Zou, L. Bertinetti, Y. Politi, P. Fratzl, W. Habraken, Small 2017, 13 , DOI: $10.1002 / \mathrm{smll} .201603100$

[68] B. Cantaert, D. Kuo, S. Matsumura, T. Nishimura, T. Sakamoto, T. Kato, Chempluschem 2017, 82, 107, DOI: 10.1002/cplu.201600457. 